\title{
Pengaruh Bahan Pakan Terhadap Jumlah Tribolium castaneum dan Susut Bobot Pakan Dalam Penyimpanan
}

\author{
Effect of Feed Ingredients on Tribolium castaneum Population and Weight Loss in Storage
}

\author{
Ardana Reswari Pratama1', Rachmat Wiradimadja', Iman Hernaman ${ }^{1 \star}$ \\ 1 Fakultas Peternakan Universitas Padjadjaran, Jalan Raya Bandung-Sumedang KM21 Sumedang 45363
}

\begin{abstract}
Abstrak
Penelitian bertujuan untuk mengetahui jumlah Tribolium castaneum dan susut bobot bahan pakan (jagung, dedak padi, pollard, kulit biji coklat, dan kulit kopi). Penelitian dilakukan dengan metode eksperimental. Rancangan percobaan yang digunakan adalah Rancangan Acak Lengkap (RAL) dengan lima perlakuan yang masing-masing diulang sebanyak empat kali. Berdasarkan analisis statistik, hasil penelitian menunjukkan bahwa pengaruh jagung, dedak padi, pollard, kulit biji coklat, dan kulit kopi tidak berbeda nyata $(\mathrm{P}>0,05)$ terhadap tingkat serangan Tribolium castaneum. Namun, pengaruh perlakuan bahan pakan nyata berpengaruh $(\mathrm{P}<0,05)$ terhadap penyusutan bobot bahan kering. Jagung menghasilkan susut bobot paling tinggi, diikuti kulit kopi dan kulit biji coklat, dan terendah dedak padi dan pollard. Kesimpulan dari penelitian menunjukkan bahwa Tribolium castaneum menyerang kelima bahan pakan, dengan jumlah penyusutan yang paling sedikit adalah dedak padi dan pollard.
\end{abstract}

Kata Kunci: jagung, dedak padi, pollard, kulit biji coklat, kulit kopi, Tribolium castaneum

\section{Abstract}

This study aims to determine Tribolium castaneum population and weight loss of feed ingredients (maize, rice bran, pollard, cocoa bean husk, and coffee husk). The research was conducted using experimental methods. The experimental design used was a completely randomized design (CRD) with five treatments, each of which was repeated four times. Based on statistical analysis, the results showed that the effect of corn, rice bran, pollard, cocoa bean husk, and coffee husk was not significantly different (P $>0.05)$ on Tribolium castaneum population. However, the effect of feedstuff treatment had a significant effect $(\mathrm{P}<0.05)$ on the depreciation of dry matter weight. Corn produced the highest weight loss, followed by coffee husk and cocoa bean husk, and the lowest was rice bran and pollard. The conclusion of the study showed that Tribolium castaneum attacked all five feed ingredients, with the least amount of shrinkage being rice bran and pollard.

Keywords: maize, rice bran, pollard, cocoa bean husk, and coffee husk, Tribolium castaneum

\section{PENDAHULUAN}

Pakan mempunyai peranan penting dalam usaha peternakan karena pakan adalah komponen input produksi yang berpengaruh langsung terhadap produksi ternak. Oleh karena itu, pemilihan bahan pakan yang tepat dalam rangka penyedian, penyusunan ransum dan pemberiannya adalah vital. Untuk mencukupi ketersedian pakan sepanjang tahun dan menghindari lonjakan harga pakan yang dapat terjadi setiap saat, pada umumnya industri peternakan ataupun koperasi-koperasi peternakan sering melakukan stok bahan pakan di tempat penyimpanan pakan atau gudang pakan. Penyimpanan dengan waktu yang relatif lama dengan pengaruh aspek lingkungan penyimpanan yang buruk, dapat menyebabkan kerusakan bahan pakan secara fisik, kimia dan biologi. Kerusakan secara biologi dapat disebabkan oleh tikus dan serangga.
Salah satu serangga hama yang merugikan adalah Tribolium castaneum termasuk serangga perusak atau pemakan hasil pertanian seperti tepung biji-bijian, beras, jagung, dedak, kopra, tepung gaplek, kacang tanah, biji pala, dan biji coklat yang disimpan dalam gudang. Tribolium castaneum merupakan jenis kumbang berwarna merah yang menyerang bahan-bahan serealia. Tribolium castaneum mengalami metamorfosis sempurna dengan empat stadia selama hidupnya, yaitu telur, larva, pupa, imago atau serangga dewasa (kumbang). Tipe tersebut juga memiliki tipe mulut pengunyah namun tidak menggigit dan dapat terbang. Kumbang betinanya dapat bertelur hingga sebanyak 450 butir dalam waktu beberapa bulan. Telur-telurnya diletakkan dekat makanannya dan berkembang sampai menjadi dewasa.

Sebagian masyarakat peternakan berasumsi kehadiran hama gudang merupakan hal yang wajar. Peternak menganggap membasminya kurang ekonomis dan tidak 
akan menyebabkan efek negatif pada bahan pakan. Padahal Tribolium castaneum sangat merugikan karena memakan komponen pati pada bahan pakan yang menyebabkan penurunan kualitas dan bobot bahan pakan. Selain itu eskresi dari kumbang dapat bersifat toksik apabila terkonsumsi oleh ternak. Toksisitas dari eskresi kumbang tersebut yang berupa urin dapat menyebabkan ganguan pencernaan bagi ternak.

Bahan pakan seperti tepung jagung, dedak halus, dedak gandum (pollard), kulit coklat dan kulit kopi merupakan bahan yang sering digunakan dalam campuran ransum ruminansia. Biasa disimpan di gudang sebagai stok dalam pembuatan ransum. Pada saat penyimpanan bahan pakan ini rentan dari serangan hama gudang. Dari kelima bahan pakan tersebut perlu diidentifikasi bahan pakan yang paling tidak disukai oleh Tribolium castaneum yang dapat digunakan sebagai campuran bahan pakan yang paling disukai Tribolium castaneum sehingga kedua jenis bahan pakan akan aman dari serangan serangga pada saat penyimpanan. Alternatif ini digunakan untuk menghindari perlakuan penanganan serangga yang mahal dan penggunaan insektisida yang pada akhirnya akan meninggalkan residu berbahaya bagi kesehatan ternak.

\section{METODOLOGI}

\section{Bahan Penelitian}

\section{Bahan Pakan}

Bahan pakan yang digunakan merupakan sumber energi. Jagung yang digunakan dalam penelitian ini berbentuk tepung jagung yang diperoleh dari CV. Missouri, Bandung, sedangkan dedak padi diperoleh langsung dari industri pengolahan padi pada saat penggilingan yang berada di Cikuda, Jatinangor, Sumedang. Dedak gandum (pollard) yang digunakan dalam penelitian ini adalah limbah industri pengolahan gandum yang diperoleh dari PT. Kadilla Lestari, Cijapati, Kabupaten Bandung. Kulit coklat berasal dari limbah industri pengolahan coklat yang diperoleh dari PT. General Food Industries yang terletak di Jalan Raya Dayeuh Kolot, Bandung. Sementara itu, kulit kopi adalah limbah industri pengolahan kopi berasal dari PT. Kadilla Lestari, Cijapati, Kabupaten Bandung.

\section{Tribolium castaneum}

Tribolium castaneum yang digunakan diperoleh dari gudang Teknologi Pakan Fakultas Peternakan Universitas Padjadjaran yang tercemar oleh Tribolium castaneum.

\section{Prosedur Penelitian}

Berbagai bahan pakan (jagung, dedak padi, pollard, kulit coklat, dan kulit kopi) terlebih dahulu disaring dengan siever. Hal ini dilakukan agar bahan pakan penelitian bebas dari kontaminan atau partikel non-bahan pakan yang akan menyulitkan perhitungan jumlah Tribolium castaneum.

Jagung, dedak padi, pollard, kulit coklat, dan kulit kopi dimasukkan ke dalam masing-masing gelas plastik sebanyak 35 gram setiap perlakuan dan ulangan. Setiap perlakuan dan ulangan dalam gelas plastik diambil 2 sampel yang masing-masing sebanyak 5 gram untuk dianalisis kadar air agar diketahui bahan keringnya. Bahan pakan perlakuan ditimbang masing-masing seberat 25 gram, diletakkan di atas piring kertas. Setiap perlakuan dan ulangan dalam piring kertas dimasukkan ke dalam baskom. Kemudian diinfestasikan Tribolium castaneum sebanyak 250 ekor ke dalam setiap baskom. Saat infestasi Tribolium castaneum digunakan lup untuk membantu memastikan jumlahnya sebanyak 250 ekor. Kemudian baskom ditutup dengan kain nylon dan diikat dengan tali karet. Udara dipastikan dapat masuk, namun tidak terdapat celah yang memungkinkan Tribolium castaneum untuk lolos dari baskom tersebut. Baskom beserta isinya disimpan di atas meja dalam ruangan laboratorium. Penyimpanan dilakukan selama 21 hari dan setiap 3 hari sekali dilakukan perhitungan tingkat serangan Tribolium castaneum. Perhitungan yang dilakukan setiap 3 hari sekali bertujuan agar tingkat serangan Tribolium castaneum dapat terlihat pada bahan pakan mana yang paling disukai dan tidak disukai. Tingkat serangan Tribolium castaneum diamati dengan menghitung jumlah Tribolium castaneum yang terdapat di setiap bahan pakan dengan menggunakan botol dan kertas sebagai media penghitungan. Setelah penyimpanan 21 hari dilanjutkan dengan menghitung bobot akhir bahan kering jagung, dedak padi, pollard, kulit coklat dan kulit kopi menggunakan cawan dan oven. Bobot susut pakan diukur dengan menggunakan timbangan digital kapasitas 150 gram dengan level ketelitian 0,001 gram.

\section{Rancangan Percobaan dan Analisis Statistik}

Penelitian ini dilakukan dengan metode eksperimental. Rancangan yang digunakan adalah Rancangan Acak Lengkap (RAL) dengan lima perlakuan yang masingmasing diulang sebanyak 4 kali sehingga diperoleh 20 unit percobaan. Data yang terkumpul dilakukan analisis Sidik Ragam kemudian dilanjutkan dengan Uji Duncan (Steel dan Torrie, 1993).

\section{HASIL DAN PEMBAHASAN}

\section{Pengaruh Perlakuan terhadap Tingkat Serangan Tribolium castaneum}

Hasil penelitian mengenai pengaruh perlakuan terhadap rataan tingkat serangan Tribolium castaneum dalam bahan pakan dengan perhitungan 3 hari sekali selama 21 hari penyimpanan disajikan pada Tabel 1 .

Data pada Tabel 1. menunjukkan urutan rataan tingkat serangan Tribolium castaneum dari yang tertinggi sampai dengan terendah adalah dedak padi (R2) 17,11 ekor, kulit biji coklat (R4) 15,36 ekor, pollard (R3) 15,32 ekor, kulit kopi (R2) 14,75 ekor dan jagung (R1) 13,46 ekor. Untuk mengetahui pengaruh bahan pakan terhadap rataan tingkat serangan Tribolium castaneum, maka dilakukan analisis ragam. Hasil analisis tersebut menunjukkan bahwa pengaruh bahan pakan tidak berbeda nyata $(\mathrm{P}>0,05)$ terhadap tingkat serangan Tribolium castaneum. 


\begin{tabular}{|c|c|c|c|c|c|}
\hline \multirow{2}{*}{ Ulangan } & \multicolumn{5}{|c|}{ Perlakuan } \\
\hline & $\mathrm{R} 1$ & $\mathrm{R} 2$ & R3 & R4 & R5 \\
\hline & & & ..ekor. & & \\
\hline 1 & 13,86 & 17,86 & 14,71 & 13,41 & 10,86 \\
\hline 2 & 11,00 & 13,86 & 17,57 & 17,00 & 19,71 \\
\hline 3 & 12,29 & 23,29 & 17,00 & 13,00 & 14,00 \\
\hline 4 & 16,71 & 13,43 & 12,00 & 18,29 & 14,43 \\
\hline Total & 53,86 & 68,43 & 61,29 & 61,43 & 59,00 \\
\hline Rata-rata & 13,46 & 17,11 & 15,32 & 15,36 & 14,75 \\
\hline
\end{tabular}

Keterangan:

R1= Tepung jagung, R2= Dedak padi, R3= Pollard, R4= Kulit biji coklat, R5= Kulit kopi.

Dalam penelitian ini digunakan sistem kafetaria. Tribolium castaneum diberi kesempatan untuk memilih bahan pakan yang disukainya. Kumbang ini dapat keluar masuk dari satu wadah bahan pakan ke wadah bahan pakan lainnya pada setiap ulangan.

Komponen bahan pakan yang dikonsumsi Tribolium castaneum adalah pati (Alanko, dkk., 2000). Semua bahan perlakuan mengandung pati, walaupun dalam jumlah yang berbeda. Kelima bahan berpotensi untuk diserang Tribolium castaneum.

Dugaan awal bahan pakan yang mengandung zat anti nutrisi seperti tannin, yaitu kulit biji coklat dan kulit kopi akan dihindari untuk diserang. Menurut Harborne (1987), tanaman yang banyak mengandung tannin pada umumnya dihindari oleh hewan pemakan tumbuhan, karena senyawa ini mempunyai rasa sepat dan dianggap sebagai penolak hewan (repellen). Namun, dari data hasil penelitian pengaruh perlakuan tidak berbeda nyata. Tribolium castaneum menyerang kelima bahan pakan tersebut.

Pati merupakan zat tepung dari karbohidrat dengan suatu polimer senyawa glukosa yang terdiri dari dua komponen utama, yaitu amilosa dan amilopektin. Bentuk dan ukuran ganula pati berbeda-beda tergantung dari sumber tanamannya (Nopianto, 2009). Tiap jenis tanaman memiliki bentuk dan kisaran ukuran

granula pati yang khas, sehingga identifikasi pati dapat dilakukan menggunakan mikroskop cahaya biasa. Pati berfungsi sebagai persediaan makanan pada tumbuhan. Pati dalam sel tanaman disimpan sebagai partikel-partikel yang tidak larut dalam air, yang dikenal sebagai granula (butir) pati. Struktur fisik dan kimia pati dalam granula dapat berpengaruh terhadap sifatnya dalam makanan (Darwindra, 2010).

Tanin berbentuk serbuk atau berlapis-lapis seperti kulit kerang, berbau khas dan mempunyai rasa sepat (astringent). Warna tanin akan menjadi gelap apabila terkena cahaya langsung atau dibiarkan di udara terbuka. Tanin mempunyai sifat atau daya bakterostatik, fungistatik dan merupakan racun (Risnasari, 2002).

Partikel pati dan tannin pada bahan serelia seperti pada kulit biji coklat dan kulit kopi tersusun dari komponen dan bentuk yang berbeda. Dalam bentuk tepung, pati dan tannin partikelnya terpisah sehingga Tribolium castaneum dengan mudah memilih dan mengkonsumsi hanya pati saja. Jadi, keberadaan tannin yang relatif tinggi pada kulit biji coklat dan kulit kopi tidak menghalangi Tribolium castaneum untuk menyerang dan mengkonsumsi bagian patinya.

\section{Pengaruh Perlakuan terhadap Susut Bobot Bahan Pakan}

Hasil penelitian mengenai susut bobot bahan pakan berdasarkan bahan kering selama penyimpanan disajikan pada Tabel 2.

Tabel 2. Pengaruh Perlakuan terhadap Susut Bobot Bahan Pakan Berdasarkan Bahan Kering Selama Penyimpanan.

\begin{tabular}{|c|c|c|c|c|c|}
\hline \multirow{2}{*}{ Ulangan } & \multicolumn{5}{|c|}{ Perlakuan } \\
\hline & $\mathrm{R} 1$ & $\mathrm{R} 2$ & R3 & R4 & R5 \\
\hline & 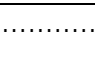 & . & .....ekor & …......... & ........... \\
\hline 1 & 1,257 & 0,580 & 0,506 & 0,704 & 0,920 \\
\hline 2 & 1,210 & 0,630 & 0,555 & 0,964 & 1,056 \\
\hline 3 & 1,395 & 0,726 & 0,502 & 1,028 & 1,320 \\
\hline 4 & 1,382 & 0,607 & 0,451 & 1,032 & 1,077 \\
\hline Total & 5,244 & 2,543 & 2,014 & 3,728 & 4,374 \\
\hline Rata-rata & 1,311 & 0,636 & 0,503 & 0,932 & 1,093 \\
\hline
\end{tabular}

Keterangan:

$\mathrm{R} 1=$ Tepung jagung, R2= Dedak padi, R3= Pollard, R4= Kulit biji coklat, R5= Kulit kopi .

Data pada Tabel 2. menunjukkan urutan tingkat penyusutan bobot bahan pakan berdasarkan bahan kering dari yang tertinggi hingga terendah adalah jagung (R1) 1,311 gram, kulit kopi (R5) 1,039 gram, kulit biji coklat
(R4) 0,932 gram, dedak padi (R2) 0,636 gram dan pollard (R3) 0,503 gram. 
Untuk mengetahui pengaruh perlakuan terhadap penyusutan bobot dalam bahan pakan, maka dilakukan analisis ragam. Hasil analisis tersebut menunjukkan bahwa perlakuan pada bahan pakan nyata berpengaruh $(\mathrm{P}<0,05)$ terhadap penyusutan bobotnya. Untuk mengetahui perbedaan pengaruh antar perlakuan dilakukan Uji Jarak Berganda Duncan dengan hasil seperti yang ditunjukkan pada Tabel 3.
Berdasarkan Tabel 3. terlihat bahwa R3 dan R2 menunjukkan susut bahan yang tidak berbeda nyata. Namun, bila dibandingkan dengan perlakuan R4 dan R5 menunjukkan jumlah penyusutan yang nyata lebih rendah. Sementara itu diantara R4 dan R5 tidak menunjukkan perbedaan yang nyata.

Tabel 3. Uji Jarak Berganda Duncan Penyusutan Bobot Pakan terhadap Perlakuan

\begin{tabular}{|c|c|c|}
\hline Perlakuan & Rata-rataBobot Susut (g) & Signifikansi $(a, 0,05)$ \\
\hline R3 & 0,503 & $\mathrm{a}$ \\
\hline $\mathrm{R} 2$ & 0,636 & a \\
\hline R4 & 0,932 & b \\
\hline R5 & 1,093 & b \\
\hline R1 & 1,311 & $\mathrm{c}$ \\
\hline
\end{tabular}

\section{Keterangan :}

Huruf yang sama ke arah kolom menunjukkan hasil yang tidak berbeda

Jagung (R1) menunjukkan jumlah penyusutan yang nyata lebih tinggi dibandingkan dengan kuli kopi (R5), kulit biji coklat (R4), dedak padi (R2), dan pollard (R3). Namun, berdasarkan tingkat serangan Tribolium cataneum, jagung tidak berbeda nyata dengan keempat bahan pakan lain.

Pengamatan tingkat penyusutan dalam keadaan tingkat serangan yang sama dapat dijelaskan dengan dugaan waktu aktivitas makan Tribolium castaneum. Pengamatan tingkat serangan Tribolium castaneum dilakukan setiap tiga hari selama penyimpanan. Hal ini dilakukan agar terlihat bahan pakan mana yang lebih dahulu disukai. Pengamatan selalu dilakukan dari pagi sampai siang hari. Dari hasil pengamatan terlihat jumlah kumbang di wadah bahan pakan selalu lebih sedikit dari pada yang terdapat di luar bahan pakan. Hal ini diduga aktivitas Tribolium castaneum lebih banyak terjadi pada saat malam hari.

Perbedaan jumlah penyusutan yang terjadi pada perlakuan penelitian diduga karena perbedaan kandungan nutrisi bahan pakan yang disukai oleh Tribolium castaneum. Nilai nutrisi makanan dan kandungan zat racun pada makanan akan menentukan kesesuaian pakan untuk menunjang berbagai proses fisiologi yang berhubungan dengan pertumbuhan dan perkembangan serangga secara optimal (Chapman 1995).

Terlihat jagung adalah sumber makanan yang paling disukai oleh Tribolium castaneum dari jumlah penyusutan bahan paling tinggi dibanding bahan pakan lainnya. Hal ini ditunjang dengan kandungan gizi utama jagung adalah pati serta lemak jagung merupakan trigliserida yang disusun oleh gliserol dan asam lemak. Kandungan pati jagung sebesar $72-73 \%$ dan asam lemak palmitat $11,1-12,8 \%$ dari total asam lemak (Rihana dan Suarni, 2009).

Kulit kopi dan kulit biji coklat bahan pakan kedua yang disukai Tribolium castaneum setelah jagung, kemudian diikuti dedak padi dan pollard. Kandungan pati pada kulit kopi dan kulit biji coklat tidak sebanyak pada dedak padi dan pollard. Namun, kandungan asam lemak pada kopi dan biji coklat sangat tinggi dibandingkan jagung, dedak padi dan pollard.

Pada kopi terdapat sukrosa 2,6\% dan isi pati kopi sangat rendah (Trigg, 2010). Sehingga, diduga kandungan pati pada kulit buah kopi lebih rendah dibandingkan dengan buahnya. Meskipun kandungan pati rendah, akan tetapi kandungan asam lemak palmitat tinggi, yaitu 38,2\% dari total asam lemak (Jham, dkk., 2008). Kulit biji coklat adalah kulit tipis, lunak dan agak berlendir yang menyelubungi biji coklat (Irawan, 1982). Pulp merupakan jaringan halus berlendir dan melekat ketat pada biji kakao mengandung glukosa $8-13 \%$, pati sedikit, sukrosa $0,4-1 \%$ (Smanda, 2008), diduga pula kandungan pati pada kulit biji coklat lebih rendah pula. Namun, kandungan lemak pada biji coklat tinggi, yaitu berkisar $55-60 \%$. Asam lemak palmitat pada lemak coklat 26,24\% dari total asam lemak (Indiarti, 2007). Pada dedak padi kandungan patinya sebesar 39,8-48,1\% (Seminar Nasional Teknik Kimia Indonesia, 2009) dan asam lemak palmitat $17,2096 \%$ dari total asam lemak (Rahmania, 2004). Pollard mengandung pati 42,95\% (Widodo, dkk., 2003) dan kandungan asam lemak palmitat diduga rendah, mengingat lemak kasar pollard hanya $1,48 \%$ (Warintek-Menteri Negara Riset dan Teknologi, 2009).

Tribolium castaneum lebih menyukai mengkonsumsi bahan pakan yang kandungan pati atau asam lemak terutama asam lemak palmitat dalam bahan pakan tinggi. Pati atau asam lemak palmitat merupakan sumber makanan Tribolium castaneum. Bahan pakan yang mengandung tepung jagung, pakan ayam fase starter dan gliserol merupakan sumber makanan bagi Tribolium castaneum. Dilaporkan pula makanan yang mengandung asam lemak terutama asam palmitat disukai oleh Tribolium castaneum (Loschiavo, 1965).

\section{KESIMPULAN}

Berdasarkan hasil pembahasan mengenai "Pengaruh Bahan Pakan terhadap Tingkat Serangan Tribolium castaneum dan Susut Bobot Pakan Selama Penyimpanan" dapat diambil kesimpulan sebagai berikut: 
1. Bahan pakan (jagung, dedak padi, pollard, kulit biji coklat dan kulit kopi) tidak memberikan pengaruh terhadap tingkat serangan Tribolium castaneum $(\mathrm{P}>0,05)$. Namun, nyata berpengaruh $(\mathrm{P}<0,05)$ terhadap penyusutan bobotnya. Jagung menghasilkan susut bobot paling tinggi, diikuti kulit kopi dan kulit biji coklat, dan terendah dedak padi dan pollard.

2. Bahan pakan yang mengalami penyusutan paling sedikit adalah dedak padi dan pollard.

\section{UCAPAN TERIMA KASIH}

Penelitian dilaksanakan di Laboratorium Nutrisi Ternak Ruminansia dan Kimia Makanan Ternak serta Nutrisi Ternak Unggas, Non-Ruminansia, dan Industri Makanan Ternak, oleh karena itu Kami mengucapkan Terimakasih kepada seluruh anggota staf dan teknisi yang telah membantu kegiatan penelitian ini.

\section{DAFTAR PUSTAKA}

Alanko, B.D., B. Richard., T.N. Sprout dan W.C.G. Furion. 2000. Warehouse Pest Management in Tropical Areas. Leigh Jhonson, Inc. Perth.

Chapman, R.F. 1995. Mechanics of Food Handling by Chewing Insects. Di dalam: Chapman RF, de Boer $\mathrm{G}$ (ed). Regulatory Mechanisms in Insect Feeding. Chapman \& Hall. New York. Hal 3-31.

Darwindra, H.D. 2010. Identifikasi Pati Secara Mikroskopis. http:// dianto.files.wordpress.com/2010/01/karbohidratii.pdf (diakses 7 September 2020).

Harborne, J.B. 1987. Metode Fitokimia. Penuntun cara modern menganalisis tumbuhan. Terjemahan Kosasih Padmawinata dan Iwang Soediro. Institut Teknologi Bandung. Bandung. Hal 85-93.

Indiarti, E. 2007. Efek pemanasan terhadap rendemen lemak pada proses pengepresan biji kakao. Jurnal Rekayasa Kimia dan Lingkungan. Vol. 6 No. 2 : 5054.

Irawan, B. 1982. Penilain Manfaat Limbah Industri Perkebunan sebagai Bahan Makanan Ternak Ruminansia secara In-Vitro. Karya Ilmiah. Fakultas Peternakan Institut Pertanian Bogor. Bogor.

Jham, G.M., A.B. Mark., K.M. Linda., A.P. Deborah dan F.V. Steven. 2008. The use of fatty acid profile as a potential marker for brazilian coffee (Coffea arabical L.) for corn adulteration. J. Braz. Chem. Soc: 19(8). São Paulo.

Loschiavo, S.R. 1965. The chemosensory influence of some extracts of brewer's yeast and cereal products on the feeding behavior of the confused flour beetle, Tribolium confusum (Coleoptera tenebrionidae). Ann. Ent. Soc. Amer. 58: 576-588.

Nopianto, E. 2009. Pengetahuan Bahan Agroindustri Pati. http://

eckonopianto.blogspot.com/2009/04/pati.html (diakses 7 September 2020).

Rahmania, O. 2004. Transesterifikasi Minyak Mentah Dedak Padi Menjadi Biodiesel dengan Katalis Asam. Thesis Program Pasca Sarjana, Jurusan Teknik Kimia Fakultas Teknologi Industri, Institut Teknologi Sepuluh November. Surabaya.

Rihana, N dan Suarni. 2009. Teknologi Pengolahan Jagung. http://

balitsereal.litbang.deptan.go.id/ind//bjagung/duatig a.pdf (diakses 14 September 2020).

Risnasari, I. 2002. Tannin. Fakultas Pertanian Jurusan Ilmu Kehutanan Universitas Sumatera Utara. Medan.

Seminar Nasional Teknik Kimia Indonesia. 2009. Ekstraksi Dedak Padi Menggunakan Isoprofil Alkohol. Program Studi Teknik Kimia, Fakultas Teknologi Industri, Institut Teknologi Bandung. Bandung.

Smanda, W. 2008. Kulit Buah Kakao, Pulp \& Biji Buah Kakao, Komposisi Kimia Pulp juga Kulit Buah. http://coklatchocolate. blogspot. com/2008/03/kulitbuah-kakaopulp-buah.html (diakses 22 September 2020).

Steel, R.G.D. and J.H. Torrie. 1993. Prinsip dan Prosedur Statistika. Edisi Kedua. PT Gramedia Pustaka, Jakarta (Diterjemahkan oleh B. Sumantri).

Trigg, C.W. 2010. The Chemistry of Coffe Bean. http://www.webbooks.com/Classics/ON/B0/B701/22MB701.html (diakses 4 September 2020).

Warintek-Menteri Negara Riset dan Teknologi. 2009. Budidaya Perikanan Pakan Ikan. Pengelolaan Data Elektronik Pemerintah Kabupaten Bantul. http://warintek.bantulkab.go.id/web.php? $\bmod =$ basi $\underline{\text { sdata \& kat }=1 \& \text { sub }=3 \& \text { file }=66 \quad \text { (diakses } 2}$ September 2020).

Widodo, Soeparno, W. Endang. 2003. Bioenkapsulasi probiotik (lactobacillus casei) dengan pollard dan tepung terigu serta pengaruhnya terhdap viabilitas dan laju pengasaman. Jurnal Teknologi dan Industri Pangan, Vol. XIV, No. 2. Yogyakarta. 